\title{
Control de fronteras y derechos humanos en el Mediterráneo
}

\author{
Borders controls and human rights in the Mediterranean Sea
}

\author{
Federico Arcos Ramírez \\ Universidad de Almería \\ farcos@ual.es \\ Eva Díez Peralta \\ Universidad de Almería \\ emdiez@ual.es
}

\begin{abstract}
Sumario: Introducción: el difícil encaje de la actual gestión de los flujos migratorios en la cultura del Estado de Derecho y los derechos humanos. 1. Derechos humanos y deberes de los Estados en las operaciones de salvamento marítimo. 2. Déficits de legitimidad en la coacción del control de fronteras. 2.1. Las carriers sanctions. 2.2. Los acuerdos de readmisión. 2.3. La instalación de concertinas y las devoluciones en caliente. 2.4. Los CIE. Reflexiones finales. Referencias.
\end{abstract}

Resumen: Este artículo trata de profundizar en algunos de los aspectos más polémicos del control tanto de las fronteras como de los flujos migratorios en el sur de Europa, con vistas a plantear una necesaria revisión de las políticas de inmigración y asilo de cara a ponerlas en consonancia con los derechos humanos más básicos y las exigencias del Estado de Derecho. Con tal propósito, se aborda, en primer lugar, los problemas que vienen presidiendo el desarrollo de las operaciones de salvamento de migrantes en alta mar, en particular la identificación de reglas claras y precisas sobre las responsabilidades de los Estados, no sólo respecto al salvamento y asistencia humanitaria en los buques, sino también en relación con el deber de facilitar el desembarco en sus puertos de las personas rescatadas. En segundo lugar, se abordan los problemas de legitimidad derivados de la mera existencia de controles coactivos en las fronteras $y$, en particular, de algunos de sus instrumentos, como las sanciones a transportistas, los acuerdos de readmisión o los Centros de Internamiento para Extranjeros, en los que el uso de la coacción resulta más discutible desde un punto de vista ético y jurídico. 
Palabras clave: políticas migratorias, derechos humanos, salvamento marítimo, legitimidad de la coacción fronteriza, acuerdos de readmisión, carriers sanctions, Centros de Internamiento para Extranjeros.

Abstract: This article analyses some of the most controversial aspects of borders control and migratory flows in southern Europe, with the aim of proposing a necessary revision of the immigration and asylum policies in order to bring them in line with the most basic human rights and the requirements of the rule of law. For this purpose, it addresses, in the first place, the problems that are presiding over the development of rescue operations for migrants on the high seas, in particular the identification of clear and precise rules on the responsibilities of States, not only with respect to rescue and humanitarian assistance on boats, but also in relation to the duty to facilitate the disembarkation in their ports of the rescued persons. Secondly, problems of legitimacy derived from the mere existence of coercive controls at the borders and, in particular, from some of its instruments, such carriers sanctions, readmission agreements or the Immigration Detention Centers, in which the use of coercion is more debatable from an ethical and legal point of view.

Keywords: migration policies, human rights, sea and rescue at sea, legitimacy of border coercion, readmission agreements, carriers sanctions, Immigration Detention Centers. 


\section{Introducción: el difícil encaje de la actual gestión de los flujos migratorios en la cultura del Estado de Derecho y los derechos humanos}

Las políticas de inmigración y asilo puestas en marcha en los últimos años por la Unión Europea no han alcanzado un equilibrio razonable entre la prerrogativa de los Estados para controlar la entrada de personas en su territorio y las exigencias del Estado de Derecho, los derechos humanos más básicos y el principio de solidaridad y de reparto equitativo de la responsabilidad entre los Estados miembros consagrado en el artículo 80 del TFUE ${ }^{1}$. La visión de los migrantes como una amenaza para la identidad cultural y política de los países europeos, la creencia en que representan también un peligro para las oportunidades laborales de los compatriotas menos aventajados o para el funcionamiento de las prestaciones asistenciales más importantes del Estado social, peligrosamente mezclado con la islamofobia indiscriminada que ha alimentado la guerra contra el terrorismo, y una visión de las migraciones como una cuestión que debe ser afrontada desde el punto de vista de la seguridad nacional antes que desde la justicia socioeconómica global, han provocado que las autoridades encargadas de diseñar y poner en práctica las medidas de control de las fronteras hayan relajado de forma alarmante la garantía de los derechos fundamentales e, incluso, de algunas exigencias puramente humanitarias ${ }^{2}$.

Sobre el actual sistema de gestión de los flujos migratorios en la ribera sur de Europa pesa la acusación de ser uno de los principales

1 Cfr. también el artículo 67.1 del TFUE. Conviene tener presente que tras la Primavera Árabe y los sucesos del sur del Mediterráneo de 2011, la Comisión presentó una serie de propuestas políticas sobre la migración, la movilidad, la integración y la protección internacional, que desarrollaban el nuevo marco general de la política exterior de la Unión en materia de inmigración y asilo, tal y como quedó reflejado en la Comunicación sobre el Enfoque Global de la Migración y la Movilidad (GAMM, por sus siglas en inglés), COM (2011) 743 final, de 18 de noviembre de 2011. En esta Comunicación, la institución comunitaria aseguraba que los derechos humanos de los inmigrantes en los países de origen, tránsito y destino, constituía un tema transversal en sus cuatro pilares de actuación, entre los que se cita, la prevención y reducción de la migración irregular y de la trata de seres humanos (p. 7).

2 La seguridad fronteriza y el respeto de los derechos fundamentales deben ir de la mano. Así las cosas, la Estrategia de Seguridad Nacional de España de 2017, al tiempo que reconoce que los flujos migratorios irregulares figuran entre los desafíos principales a los que se enfrenta la seguridad de nuestro país, también incorpora el aserto de que nuestro Estado debe desplegar «esfuerzos por proteger los derechos humanos de aquellos que se encuentren en situación de mayor vulnerabilidad». Estrategia de Seguridad Nacional 2017. Un proyecto compartido de todos y para todos, p. 72. 
responsables de que el mare nostrum se haya convertido en el mayor cementerio del mundo, en la frontera más mortífera del planeta, con más de 15.000 migrantes y refugiados muertos desde 2014 (Last et al. 2017). Si la proporción inversa entre la tasa demográfica y la media de edad de los países del sur respecto a la riqueza de los Estados europeos ribereños del Mediterráneo convierte a nuestro mar interior en la falla demográfica más importante del planeta ${ }^{3}$, los datos de la Organización Internacional para las Migraciones (OIM) y del Alto Comisionado de las Naciones Unidas para los Refugiados (ACNUR) añaden el elemento trágico de que las aguas del Mediterráneo son las más peligrosas del mundo en términos de número de muertos y desaparecidos entre quienes se embarcan en el sur para tratar de ganar las costas europeas ${ }^{4}$.

Una realidad tan abrumadora indica, como mínimo, que algo está fallando en la gestión de las fronteras por parte de la Unión Europea y, en particular, de los Estados ribereños del Mediterráneo. Este control no tanto ya de fronteras como de los flujos migratorios se articula a través de políticas basadas en una filosofía restrictiva, reactiva y preocupada únicamente en la seguridad y no, como sería lo deseable, en la innovación y el desarrollo y centrada en los factores sociales y económicos que los originan ${ }^{5}$. De ahí la necesidad de profundizar en los aspectos más importantes a la vez que polémicos del control tanto de las fronteras como de los flujos migratorios en el sur de Europa, de cara a plantear una necesaria revisión de las políticas de inmigración y asilo a la luz de las exigencias de los derechos humanos más básicos. Porque, junto al coste en vidas humanas señalado, otro de los principales damnificados por las respuestas adoptadas por los gobiernos de los países europeos mediterráneos en materia de políticas migratorias y de asilo está siendo el valor jurídico de los derechos humanos y el respeto

3 Europa es la única región del mundo que tendrá menos población en 2050 que en 2017; en África y Asia, entre 2017 y 2050 se espera un crecimiento de la población de 1,3 billones y de 750 millones de personas, respectivamente; más allá de 2050, África será el principal contribuyente al crecimiento de la población mundial. Cfr. World Population Prospects. The 2017 Revision. Key Findings and Advances Tables, United Nations, New York, 2017, ESA/P/WP/248, p. 3.

4 No obstante, los datos del Proyecto Migrantes Desaparecidos, compilados por el equipo de la Organización Internacional de las Migraciones, y consultados durante la redacción de este trabajo, ponen de relieve que, entre el 1 de enero y el 18 de abril de 2018, se contabilizaron 559 migrantes fallecidos en el Mediterráneo, frente a los 1.091 que desaparecieron en 2017, en el mismo periodo. A pesar de que el número de muertos ha disminuido durante el primer trimestre del año en curso, sin embargo, las cifras siguen siendo muy elevadas en comparación con otros lugares y regiones. Más información en http://missingmigrants.iom.int/methodology.

5 Véase, ampliamente, Zapata (2013). 
de las exigencias más básicas del Estado de Derecho. Entre otros, viene denunciándose la creación de verdaderos limbos jurídicos como los $\mathrm{CIE}$, de espacios de infraderecho, el cuestionamiento de la vigencia del principio de estricta legalidad, en virtud del cual el uso legítimo del ius puniendi se contempla a partir de lo que se hace (o no) pero nunca de lo que se es (o no) (Martínez Escamilla 2015), o la consolidación de un auténtico infraderecho administrativo puramente vejatorio integrado por un «sotobosque de circulares ministeriales y ordenanzas municipales antiextranjeros, todas persecutorias de diversas maneras y en gran medida ilegítimas» (Ferrajoli 2011, 69). La articulación jurídica del control de fronteras parece obedecer, por todo ello, más a la lógica del estado de excepción o de seguridad que a la de un Estado de Derecho (Lucas 2014, 50; Agamben, 2004).

Para ello es necesario, como paso previo, profundizar algo más de lo que hemos hecho hasta ahora, en algunos de los principales rasgos de la evolución de las políticas migratorias europeas. Así, en un proceso cuyo origen se remonta a la década de los ochenta y que adquirió fuerza y velocidad con el Tratado de Ámsterdam en 1999, podría decirse que el control de los flujos migratorios en la Unión Europea ha experimentado la siguiente evolución ${ }^{6}$ : a) se ha extraterritorializado y/o externalizado, al asumir una dinámica de «control remoto» (Zolberg 2003) o desplazamiento de las tareas de control migratorio fuera del territorio europeo y hacia terceros países, a través de la política de visados o de centros de procesamiento externos; b) se ha militarizado, como sería el caso de la Operación EUNAVFOR MED Sophia, una misión militar en el Mediterráneo central que está pensada, en términos generales, para luchar contra los tráficos ilícitos de personas, el control de los flujos de inmigración irregular y evitar más pérdidas de vidas humanas en el mar; c) es cada vez más transnacional, como

6 Unas interesantes reflexiones sobre la evolución de la gestión de la actual ola migratoria por parte de la Unión Europea pueden verse en Attiná (2018).

7 Posteriormente, se ha prorrogado su mandato y se le han encomendado dos tareas más dentro de la zona de operaciones acordada: de un lado, la asistencia en la creación de capacidades y en la formación de la guardia costera y la armada Libias en alta mar; y, de otro lado, contribuir a la aplicación del embargo de armas de las Naciones Unidas en alta mar frente a las costas de Libia, a través de inspecciones de buques con origen o destino a Libia, a tenor de lo dispuesto en la Resolución 2292 (2016) del Consejo de Seguridad. Como se ha señalado, esta operación «constituye una prueba de la creciente conexión entre las actividades externas e internas en el ámbito de la seguridad, en la medida en que vincula las acciones militares PCSD con la misión de Frontex» (Díez Peralta 2017, 205). 
prueba la existencia de una Guardia Europea de Fronteras y Costas 8 ; d) se ha vuelto más sofisticado e inteligente, incorporando técnicas empleadas por los servicios de inteligencia y en el ámbito militar (Zaiotti $2016,7)^{9}$; e) es "flotante», como en el caso del Sistema Europeo de Vigilancia de Fronteras (Eurosur), que utiliza aviones, satélites, sensores marinos y drones, para rastrear poblaciones móviles (Baird 2018, 118-119; Spijkerboer 2018, 216-217); e) se ha privatizado, ya que, tanto en la pre-frontera, como en la frontera y la post-frontera, las empresas privadas están involucradas en el control de la inmigración irregular a través de la tramitación de visados, la selección, el filtrado, la identificación y el registro de los flujos de migrantes, así como su detención, atención y transporte (Sala y Godenau 2017, 207-208), y f) se ha endurecido, con la construcción de nuevos muros y vallas a lo largo de las fronteras territoriales, como ha sucedido en Hungría y Bulgaria.

Centraremos nuestro interés en dos aspectos de la actual gestión de los flujos migratorios en el Mediterráneo que ponen de manifiesto la dificultad o la incapacidad de los países de la UE para tomarse en serio los derechos humanos de los migrantes. En primer lugar, abordaremos los problemas que vienen presidiendo el desarrollo de las operaciones de salvamento de migrantes en alta mar, en particular la identificación de reglas claras y precisas sobre las responsabilidades de los Estados, no sólo respecto al salvamento y asistencia humanitaria en los buques, sino también en relación con el deber de facilitar el desembarco en sus puertos de las personas rescatadas. En segundo lugar, dedicaremos el grueso de este artículo a abordar los problemas de legitimidad derivados de la mera existencia de controles coactivos

8 Aunque los Estados son los principales responsables de gestionar las fronteras exteriores, la supresión de las fronteras interiores de la Unión conlleva necesariamente la instauración de una cooperación entre los Estados miembros y esta nueva Agencia europea, que viene tanto a sustituir a Frontex como a aumentar las capacidades operativas de la que fue su antecesora. Vid. Reglamento (UE) 2016/1624 del PE y del Consejo, de 14 de septiembre de 2016, sobre la Guardia Europea de Fronteras y Costas, por el que se modifica el Reglamento (UE) 2016/399 del PE y del Consejo y por el que se derogan el Reglamento (CE) n. ${ }^{\circ} 863 / 2007$ del PE y del Consejo, el Reglamento (CE) n. ${ }^{\circ}$ 2007/2004 del Consejo y la Decisión 2005/267/CE del Consejo (DOUE L 251/1, de 16 de septiembre de 2016). Un análisis y valoración de esta normativa puede verse en Soler (2017).

9 Un claro exponente, los controles automatizados de fronteras. Estos sistemas, conocidos como ABC (Automated Border Control), incluyen tecnologías avanzadas de validación documental y biométrica. Los sistemas funcionan mediante el uso de pasaporte y DNI electrónicos e incorporan reconocimiento biométrico, tanto facial como dactilar, para la identificación de los viajeros. 
en las fronteras y, en particular, de algunos de sus instrumentos en los que, a excepción de las vallas y concertinas, el uso de una coacción delegada y/o encubierta hace aún más problemática su justificación moral y política.

\section{Derechos humanos y deberes de los Estados en las operaciones de salvamento marítimo}

Uno de los principales desafíos a los que se enfrentan actualmente la Unión Europea y, en particular, los Estados de su frontera mediterránea es poner en marcha operaciones que aseguren tanto el salvamento como el desembarco en un puerto seguro de los migrantes rescatados en sus aguas.

Como fundamento jurídico de las operaciones de rescate de migrantes en alta mar se señala el deber contenido en el artículo 98 del Convenio de las Naciones Unidas sobre el Derecho del Mar de $1982^{10}$. De tal precepto parece desprenderse un deber humanitario casi absoluto e incondicionado de rescate, no sujeto a ponderaciones con valores como el orden público o el interés general y, sobre todo, con consideraciones basadas en el coste económico que ello pueda suponer para la compañía o Estado al que pertenezca el buque. En contra de este deber, se señala que el mismo estaría generando un efecto llamada, que provoca aún más muertes que las que tratan de evitar las operaciones de salvamento marítimo e, incluso, que quienes se suben a esos barcos atestados estarían aprovechándose de la buena voluntad de los países de la Europa mediterránea (e indirectamente de la Unión Europea). En el plano de la filosofía política, algunos teóricos defensores de una concepción estatista de la justicia internacional han planteado la conveniencia de enfocar el problema del rescate de migrantes en alta mar desde una perspectiva consecuencialista, que tome en consideración no solo la salvaguarda de vidas humanas sino también las consecuencias del "efecto llamada» que dichas operaciones de rescate pueden provocar. Algunos creen que estos rescates sirven para alentar a más inmigrantes a cruzar el mar, por

10 «Todo Estado exigirá al capitán de un buque que enarbole su pabellón que, siempre que pueda hacerlo sin grave peligro para el buque, su tripulación o sus pasajeros: a) preste auxilio a toda persona que se encuentre en peligro de desaparecer en el mar; b) se dirija a toda la velocidad posible a prestar auxilio a las personas que estén en peligro, en cuanto sepa que necesitan socorro y siempre que tenga una posibilidad razonable de hacerlo». 
lo que es concebible que, en conjunto, terminen perdiéndose más vidas si se llevan a cabo acciones de rescate que si no se realizan ${ }^{11}$. Resulta particularmente interesante detenerse en las claves de este argumento que, con mayor o menor sutileza, está detrás de algunos de los discursos que justifican el rechazo a acoger más refugiados $y$, en general, que abogan por un endurecimiento de la gestión de los flujos migratorios en el Mediterráneo. Para hacerlo, examinaremos las principales claves de la perspectiva que ha desarrollado sobre el tema David Miller.

A juicio del conocido pensador político británico, no es posible explicar la naturaleza y límites del deber de rescatar a los migrantes en alta mar a partir, exclusivamente, del artículo 98 del tratado reseñado. En su opinión, la visión del deber de rescate marítimo como un deber fuerte, que funciona como una razón perentoria, insensible a las consecuencias que puedan derivarse de su cumplimiento, no toma en consideración los siguientes factores (Miller, 2015; Miller 2016, 171). En primer lugar, la distinción entre las personas o equipo de personas que se enfrenta de modo directo a una situación de rescate y los agentes colectivos, como los gobiernos, que deciden establecer un sistema diseñado para cubrir un conjunto de futuras eventualidades. En el último caso, sí resultaría pertinente tomar en consideración, no solo las vidas e integridad física en juego en un acto concreto de rescate, sino las consecuencias globales que se derivan del sistema propuesto. En segundo lugar, aunque no termine de afirmarlo de forma expresa, Miller deja entrever cómo, a la hora de determinar la intensidad del deber en cuestión, resulta decisivo precisar si los países sobre los que recae la obligación del rescate tienen contraídas responsabilidades reparativas con las personas a bordo. Entre estas, hay tanto migrantes económicos, como demandantes de asilo que huyen de una persecución por motivos políticos y refugiados que pueden reclamar justificadamente que

11 Un claro ejemplo de esta visión fueron las declaraciones que realizó en la Cámara de los Lores el 15 de octubre de 2014 la Ministra de Asuntos Exteriores de Reino Unido, Joyce Anelay, para justificar la negativa de su gobierno a sufragar la operación Tritón: «No apoyamos las operaciones planificadas de búsqueda y rescate en el Mediterráneo. Creemos que, involuntariamente, crean un "efecto llamada" que alienta a más inmigrantes a intentar cruzar el peligroso mar y, por lo tanto, más muertes trágicas e innecesarias. El Gobierno cree que la forma más efectiva de evitar que los refugiados y migrantes intenten esta travesía peligrosa es centrar nuestra atención en los países de origen y tránsito, así como tomar medidas para luchar contra los traficantes de personas que voluntariamente arriesgan vidas embarcando a los migrantes en barcos no aptos para la navegación». Disponible en https://publications.parliament.uk/pa/ld201415/ Idhansrd/text/141015w0001.htm (fecha de consulta: 10 de octubre de 2018). 
escapan de conflictos causados parcialmente por la intervención de los países occidentales. En tercer lugar, aunque no puede ignorarse que muchas de las personas suben a estas embarcaciones (pateras, lanchas neumáticas, viejos pesqueros, etc.) lo hacen desesperadamente, movidos por una fuerte necesidad de fuga, de huida de la persecución o la pobreza extrema y que, por esta y otras razones, su decisión no es plenamente racional y completamente autónoma; en cierta medida, los migrantes son responsables de sus propias dificultades, ya que se han situado de forma activa en una posición en la que el rescate es necesario. En cuarto lugar, no puede dejar de tenerse en cuenta que no existe en el plano jurídico internacional un deber de los Estados de autorizar el desembarco en su territorio de las personas rescatadas en el mar. Existen ejemplos históricos muy conocidos, en los que se ha obligado a un barco a navegar miles de millas hasta encontrar un puerto en el que poder anclar y desembarcar a sus ocupantes (el más famoso, el del MS St. Louis en 1939 y el más reciente, las mil quinientas millas recorridas por el Aquarius en junio de este año, desde la costa libia hasta el puerto de Valencia). Por todo ello, Miller concluye que el deber de rescate es un derecho relativamente débil, cuya fuerza no vendría determinada exclusivamente por el beneficio que proporcione a las personas atendidas, sino también por otros factores, como el coste de hacerlo efectivo, la responsabilidad del beneficiario en sus propias dificultades, etc.

Ciertamente, no puede afirmarse rotundamente que, de modo expreso, la legalidad internacional contenga criterios que permitan establecer si cierto Estado tiene la obligación de autorizar el desembarco en territorio de las personas rescatadas en el mar. Sin embargo, una lectura conjunta de los párrafos 2.1 y 13.2 del Convenio internacional sobre búsqueda y salvamento marítimo (Convenio SAR versión 1979), la regla 33.1 del Convenio internacional sobre seguridad de la vida humana en el mar (Convenio SOLAS) y las Directrices respecto de la actuación con personas rescatadas en el mar, incluida en la Resolución MSC 167 (78) 2004, del Comité de Seguridad Marítima, permiten sostener la existencia de un deber jurídico y no sólo humanitario de rescate y acogida en tierra de los migrantes embarcados ${ }^{12}$. En estas últimas se indica que el Gobierno responsable de la región SAR (zona

12 Para Javier de Lucas, todas estas normas vinculan, establecen obligaciones jurídicas a los Estados partes en esas convenciones y tratados. Por tal razón el incumplimiento de esas obligaciones es una grave infracción jurídica, no simplemente una tragedia, ni un problema humanitario, sino que lo que está en juego son los derechos básicos de los seres humanos (Lucas 2014, 97-99). 
de búsqueda y rescate, del inglés ), en la cual fueron rescatadas dichas personas, es el principal responsable de brindar o asegurarse de que se brinda un lugar seguro. Además, rechazar un barco que acaba de socorrer a personas que requieran curas médicas urgentes o elementos de primera necesidad como comida, agua o medicinas, podría violar los artículos 2 (derecho a la vida) y 3 (derecho a no ser torturado) de la Convención Europea de Derechos Humanos.

Por otra parte, existe una praxis consolidada por la cual, una vez que un barco ha entrado en aguas territoriales de un Estado, aquel ya no puede ser rechazado (Ghezelbash et al. 2018, 336), debido a que entre sus pasajeros puede haber quienes necesiten asistencia o tengan derecho a solicitar protección internacional. Este es, con seguridad, el aspecto decisivo. Entre las personas rescatadas en el mar hay quienes huyen de países en los que son perseguidos y se exponen a ser encarcelados, torturados o asesinados en caso de ser devueltos a sus países de origen, especialmente en los últimos años en los que ha ido aumentando el carácter mixto de los flujos migratorios ${ }^{13}$. Ante las enormes dificultades que supone distinguir en alta mar si las personas rescatadas son migrantes económicos o potenciales demandantes de asilo, no parece que pueda admitirse que exista otra alternativa que admitir que algún Estado que reúna las condiciones deba asumir la responsabilidad de permitir su desembarco ${ }^{14}$.

Por otra parte, diferentes informes desmienten el «efecto llamada» de las operaciones humanitarias de rescate. Estos revelan que, tras los intentos de travesía marítima durante los períodos en los que estuvieron

13 Reglamento (UE) 656/2014 del Parlamento europeo y del Consejo de 15 de mayo de 2014, por el que se establecen normas para la vigilancia de las fronteras marítimas exteriores en el marco de la cooperación operativa coordinada por la Agencia Europea para la Gestión de la Cooperación Operativa en las Fronteras Exteriores de los Estados miembros de la Unión Europea. En el artículo 10.1 a) se dice que «en caso de interceptación en el mar territorial o en la zona contigua, según se contempla en el artículo 6, apartados 1, 2 ○ 6, o en el artículo 8, apartados 1 o 2, el desembarco se realizará en el Estado miembro ribereño, sin perjuicio de lo dispuesto en el artículo 6, apartado 2, letra b). DO L 189 de 27.6.2014, p. 93.

14 En su Resolución 2229 (2018), considerando 5.3, la Asamblea Parlamentaria del Consejo de Europea reclama «separar las operaciones de rescate llevadas cabo por los Estados de las subsiguientes demandas de asilo por parte de aquellos rescatados en el mar, ya que ambas suponen obligaciones diferentes de los Estados». Hubiera sido razonable y deseable que esta separación hubiera incluido también al deber de admitir el desembarco de los rescatados en sus costas, lo cual sin duda facilitaría que algunos se muestren menos reacios, tal y como está ocurriendo con Italia y Malta, a que la región SAR se establezca dentro de sus aguas territoriales en todos aquellos casos en los que no puede determinarse donde tiene lugar la operación de rescate. 
activas las operaciones Mare-Nostrum, Tritón y, posteriormente, los buques de las ONG humanitarias (Aquarius, Open Arms, SOS Mediterranée, Médicos sin Fronteras, etc.), se observa una migración temporal/estacional que no está siendo disuadida, pero tampoco promovida, por las operaciones de rescate. Los factores impulsores de la migración, como los conflictos, las persecuciones, la sequía y la pobreza, probablemente desempeñarán un papel importante en el medio de la compleja mezcolanza de factores asociados a la migración. Si la hipótesis del efecto llamada tuviera fundamento, el número total de intentos de travesías marítimas a partir del momento en que comenzaron a operar los buques humanitarios debería haber sido considerablemente mayor que el de las realizadas durante el período equivalente en que estuvo operativa la operación Tritón. Sin embargo, esto no ha ocurrido, con lo que quedaría desacreditada la hipótesis de que la búsqueda y el rescate han tenido el «efecto llamada» que se les ha atribuido (Arsenijevic et al., 2017).

\section{Déficits de legitimidad en la coacción de los controles fronterizos}

Una de las dimensiones más conflictivas de cualquier política migratoria y, en particular, de las desarrolladas en el Mediterráneo, se refiere al carácter coactivo de los controles fronterizos. Desde el punto de vista no solo ético y político sino también jurídico, resulta problemática la coacción empleada en gran parte de las medidas dirigidas a evitar la entrada de personas en el territorio de estos Estados. De acuerdo con la visión hobessiana aún dominante de la soberanía, a nivel interno, los Estados detentan la autoridad política última y absoluta sobre su territorio y población; en el plano externo, no están sujetos a ningún otro poder externo; y, por lo que respecta a los límites entre una y otra dimensión, tienen el derecho unilateral y soberano de determinar quién puede cruzar sus fronteras y de acuerdo con qué requisitos o condiciones ${ }^{15}$. Este enfoque resulta cuestionable desde el punto de vista de cualquier visión de la legitimidad política $y$, en particular, de la democrática ${ }^{16}$. En diferentes trabajos, Arash

15 Sobre los fundamentos filosóficos de esta visión de la soberanía vid. Ferrajoli (1998).

16 Como destaca Garzón Valdés $(1993,388)$, la soberanía es simplemente la capacidad de un Estado para imponer libremente sus normas jurídicas a una población que se halla en un territorio determinado y ello no implica necesariamente ningún status moral que, en tanto tal, merezca un respeto incondicional. 
Abizadeh ha defendido la tesis de que, puesto que las personas sometidas a los controles fronterizos de una comunidad política delimitada son tanto sus miembros como no miembros, la justificación de los mismos debe tomar en consideración tanto a los primeros como a los segundos. Asumiendo como premisa previa que la teoría democrática de la soberanía popular presupone tácitamente que el demos al que se debe la justificación democrática se haya, en principio, indeterminado (unbounded), Abizadeh concluye que, si todos los sujetos al poder político no participan en la determinación de las normas a través de las cuales aquel actúa, tal ejercicio carecerá de uno de las bases más importantes de la legitimidad democrática. Por lo que se refiere particularmente a las fronteras, ésta exige que su régimen jurídico sea determinado a través de procesos políticos en los que los extranjeros tengan la posibilidad de participar (Abizadeh 2008, 44 y ss).

Como reconoce Abizadeh, la traducción institucional de la legitimidad democrática del control de las fronteras resulta muy compleja y no pretende adoptar como procedimiento de decisión una regla de la mayoría en la que el voto de los ciudadanos y los extranjeros tengan el mismo peso. En última instancia, reconoce que las posibles justificaciones de las restricciones fronterizas exigen la creación de instituciones cosmopolitas o trasnacionales que permitan la articulación de un demos global y que posean jurisdicción para determinar las políticas de admisión, o para delegar legítimamente esta función a los Estados particulares o a otras instituciones. Insiste por ello en que la legitimidad democrática obliga a los Estados a apoyar la creación de estas instituciones globales (Abizadeh 2008, 54).

No creemos, sin embargo, que el legitimacy gap señalado por Abizadeh que padecen los controles fronterizos pueda ser superado a través de una democracia cosmopolita. Además de que, en el plano estrictamente normativo, supondría cuestionar la división del espacio político por Estados, una democracia global impone un cambio de escala que ha sido seriamente cuestionado, entre otras razones porque la democracia trasnacional necesita un Estado mundial, y ésta es una alternativa al actual sistema de Estados separados que tiene muchos menos defensores que detractores (Bayón 2014, 133; Scheurmann 2014). La solución más razonable es considerar que la legitimidad democrática no exige tanto, ni principalmente, la participación de todos los afectados por una decisión en el procedimiento de adopción de ésta, como la asignación de responsabilidad a quien la adopta de proteger los intereses y derechos de todas las personas afectadas por 
ella. Esto se traduce, fundamentalmente, en la exigencia de respetar y proteger los derechos humanos de esas personas ${ }^{17}$.

Desde esta concepción de la legitimidad de las fronteras examinaremos aquellas medidas coactivas que más críticas vienen recibiendo por conculcar derechos humanos básicos. Una nota común a muchas de ellas es que la coacción aparece difuminada, cuando no oculta, lo que hace mucho más difícil su control y la determinación de las responsabilidades derivadas de su ejercicio. Algunas de ellas se enmarcan, fundamentalmente, en la dimensión de externalización del control de fronteras antes señalada (Abrisketa 2017, 125-131). Al objeto de lograr un reforzamiento de las fronteras exteriores comunes, desde hace más de una década, España y otros países de la Unión Europea han suscrito numerosos acuerdos bilaterales con los países de la ribera sur del Mediterráneo y, más recientemente, con los de la región subsahariana, a través de los cuales se acuerda una auténtica deslocalización del control de la migración, cuyo núcleo es la noción de "políticas de control remoto», que implican el desplazamiento del lugar de control más allá del territorio común. Sus instrumentos incluyen tanto las tradicionales políticas de visado, como las más novedosas sanciones a transportistas (carriers sanctions) a través de la Directiva 2004/82/CE, el procesamiento de las demandas de la gestión de los flujos migratorios fuera de la UE. Es en la frontera donde la gestión de los flujos migratorios recurre a las formas de coacción más visible y directa para reprimir la entrada en su territorio: el uso de vallas, concertinas, pelotas de goma y aerosoles de gas pimienta y el recurso a las devoluciones en caliente. Ya en territorio de los Estados, en el caso de que las personas migrantes logren traspasar las fronteras europeas, también existen zonas grises u opacas de coacción, tanto en los acuerdos de readmisión, como en los centros de internamiento donde se recluye temporalmente a los migrantes pendientes de un procedimiento de expulsión ${ }^{18}$.

17 Seguimos aquí un argumento similar al defendido por Cristina Lafont (2010) para construir su crítica a la concepción estatista de los derechos humanos. Por eso, el propio Abizadeh tiene que terminar admitiendo que «the most plausible models of democratic legitimation take seriously the dual commitment to the democratic principle of popular sovereignty, on the one hand, and the rule of law, human rights, and groupdifferentiated rights on the other» (Abizadeh 2010, 160).

18 Así, por ejemplo, el acuerdo entre España y Senegal, de 2007, supone para este último país la aceptación de la readmisión de migrantes interceptados en España o en ruta hacia las Islas Canarias, ya sean nacionales o de terceros países, la colaboración en la identificación de migrantes y su redocumentación a través de oficiales senegaleses presentes en los centros de detención en el archipiélago, el control de las salidas de 


\subsection{Las carriers sanctions}

Las sanciones a los transportistas constituyen una de las principales herramientas para garantizar el control de la migración antes de la llegada y un obstáculo importante para que muchos migrantes y refugiados puedan alcanzar el territorio del Estado en el que pretenden ingresar a través de un viaje regular. Como dispone la sección 26 del Acuerdo de Schengen, representan una situación en la que un Estado impone sanciones en forma de multas (o, en algunos casos, la pérdida de privilegios de aterrizaje), junto con la asunción de responsabilidad para acomodar y repatriar a los migrantes sin papeles o con una documentación incorrecta, tanto a líneas aéreas como a compañías navieras y empresas de transporte terrestre. Se trata de una medida fundamental de "control remoto" de los Estados (los controles se llevan a cabo en los puertos de partida) y uno de los principales ejemplos de la desnacionalización de la gestión de la migración. Actualmente, se encuentran reguladas en la Directiva 2001/51/CE de 28 de junio de $2001^{19}$.

Muchos estudios consideran que, tal y como están reguladas, las sanciones a los transportistas tienen efectos perjudiciales sobre los derechos fundamentales y son dañinas para los solicitantes de asilo que necesitan protección internacional. En relación con el Sistema Europeo Común de Asilo (CEAS), las conocidas como medidas de interceptación administrativa o pasiva ${ }^{20}$, entre las que se incluyen los visados y las sanciones a los transportistas, pueden, bajo ciertas condiciones, violar el Derecho internacional de los derechos humanos. Si los defectos en la documentación se identifican cuando ya se está en tránsito, la intercepción de un refugiado fuera del país de su nacionalidad, siempre que implique el retorno de la persona al territorio donde sufre persecución, puede constituir una violación de la prohibición de expulsión y devolución o «non-refoulement» contenida en el

embarcaciones desde sus costas, la presencia de oficiales de enlace españoles en el país, la extensión de las operaciones de Frontex en sus aguas y el establecimiento de patrullas bilaterales con España. Este compromiso está recogido en un Memorandum de Entendimiento no publicado en el BOE. Se trata de una fórmula ya utilizada en 2006 para establecer compromisos similares entre España y Mauritania.

19 DO L n. ${ }^{\circ} 187$, de 10.07.2001, p. 45.

20 La distinción, dentro de las medidas adoptadas por los Estados para prevenir, interrumpir o detener el movimiento de personas sin la documentación necesaria para cruzar sus fronteras por tierra, mar o aire, entre medidas de interceptación física o activa (como la interceptación de busques en alta mar) y administrativa o pasiva es de Goodwin y Mcadam (2007, 371-372). 
artículo 33.1 del Convenio de Ginebra de 1951 sobre el Estatuto de los Refugiados (Moreno-Lax 2008).

Algunos Estados miembros, en particular Alemania, consideran que las sanciones a los transportistas serían ineficaces si se permite una excepción para los solicitantes de asilo. No obstante, durante la tramitación de la redacción y aprobación de la Directiva 2001/51, Francia propuso que los transportistas quedaran exentos de sanciones cuando el nacional de un tercer país fuese un demandante de asilo. Finalmente, el texto final de la Directiva incluye una referencia dirigida a evitar que se ignoren las obligaciones de proteger a esas personas ${ }^{21}$, pero no incluye ningún deber o incentivo para que el transportista diferencie en su decisión entre quienes son o no demandantes de asilo (Peers 2016, 472). En la práctica, solo la mitad de los Estados miembros han transpuesto posteriormente la Directiva de manera que se tome en consideración la situación de los refugiados y solicitantes de asilo. De acuerdo con un estudio realizado por el Consejo Europeo sobre Refugiados y Exiliados, Francia, Italia y los Países Bajos no aplican multas si una persona era admitida en su procedimiento de asilo, mientras que Dinamarca, Alemania y el Reino Unido sí lo hacen (Mac Namara 2017).

Además de ser un claro exponente de la cada vez más pronunciada tendencia hacia la «privatización» o outsourcing de las políticas europeas de control de fronteras 22 , las carrier sanctions constituyen una forma de coacción oculta que, como se ha señalado, puede poner en peligro a personas demandantes de asilo. Como explican Bloom y Risse $(2014,78)$, la coerción generalmente ejercida por el Estado

21 Cuando en el considerando 3 del Preámbulo señala que «La presente Directiva debería aplicarse sin perjuicio de los compromisos que resultan de la Convención de Ginebra de 28 de julio de 1951 sobre el Estatuto de los Refugiados, tal como fue modificada por el Protocolo de Nueva York de 31 de enero de 1967».

22 De acuerdo con SOS Racismo, todos los productos médicos suministrados a los CIES se delegan al sector privado. Esta subcontratación también se presenta en centros de alojamiento temporal o CETI. En 2013, las empresas españolas EULEN Seguridad y Serramar Vigilancia y Seguridad firmaron con el Ministerio del Interior un contrato por un valor de 6,5 millones de euros para la vigilancia del CETI de Ceuta y Melilla. Otro tanto ocurre con la construcción de las vallas en estos dos enclaves - que supusieron un desembolso de 72 millones de euros entre 2005 y 2013, según un informe de Amnistía Internacional- y el Sistema Integrado de Vigilancia Exterior (SIVE) de las costas — que implicó un gasto ulterior de unos 230 millones de euros entre 2000 y 2008-, tras los que se encuentran empresas como Indra o Dragados. Entre 2005 y 2015, el gobierno español ha pagado más de 60 millones de euros a empresas contratadas para construir, ampliar y mantener instalaciones fronterizas. Vid. Centre delàs d'estudis per la Pau (2018), Akkermann (2018), López Sala y Godenau (2016), López Sala y Godenau (2017). 
en su frontera es trasladada a empresas privadas que operan en el territorio de otro Estado, que también se encargan, indirectamente, de establecer las condiciones de entrada, ya que deben determinar a qué personas se les obligará a retornar, lo que termina traduciéndose en la imposición de unas condiciones de entrada más exigentes que las establecidas oficialmente por el Estado. La coerción no está dirigida explícitamente por el Estado hacia los migrantes potenciales, sino que se oculta a través de otro tipo de coacción impuesta a los transportistas privados. Y puesto que tanto la aplicación de la fuerza como la toma de decisiones sobre su uso en la frontera son sucesivamente delegadas, se hace difícil determinar el papel jugado realmente por el Estado en ambos momentos 23 .

Por todo ello, la necesidad de legitimación de la coacción señalada por Abizadeh resulta aquí especialmente intensa, ya que se trata de un tipo de coacción que sufre un considerable déficit de transparencia y de control. La transparencia desaparece debido a que esta coacción se mueve a un área opaca que es prácticamente invisible para el demos. Esto ocurre de dos formas. En primer, porque se oculta el verdadero significado de la decisión política por parte del Estado, ya que su plasmación normativa se realiza en un contexto que, necesariamente, obliga a su posterior reinterpretación por actores no estatales en el momento de su ejecución. Así, por ejemplo, si un Estado deja claro que aceptará a todos aquellos que acrediten una demanda humanitaria de nivel $X$, y a la mayoría de aquellos de nivel $Y$, se incentivará a que la empresa privada con márgenes de ganancia ajustados rechace a aquellos que solo tienen el nivel de prueba $Y$, por temor a la sanción, y aceptar a la mayoría de los que tienen el nivel de prueba $X$. En segundo lugar, las carriers sanctions ocultan la coerción al desdoblar los niveles en los que las personas están sometidas a ella. Aunque la persona sobre la que pretende ejercerse la coacción fronteriza es el potencial migrante, el Estado canaliza su ejercicio a través de las compañías de transporte, de modo que aquél solo se involucra indirectamente en su ejercicio. Por lo que se refiere al control de la coacción, la delegación de su ejercicio a actores privados impide que pueda estar sometida a controles democráticos y jurídico-constitucionales. La coerción ejercida por los actores estatales ya sea dentro del territorio del Estado como en las

23 Como señala Baird (2017), las carriers sanctions conllevan una redefinición de las relaciones entre los estados, las empresas y las personas que se traduce en una disminución de las obligaciones éticas y jurídicas de los Estados y las empresas hacia las poblaciones que necesitan protección, que vuelve borrosas las líneas que delimitan las responsabilidades de unos y otros cuando se producen abusos. 
fronteras estatales, suele estar sujeta a mecanismos de control judicial y a las exigencias del rule of law. La que ejercen los actores privados, como sería el caso de las aerolíneas, no está sujeta al mismo régimen legal, ni pueden ser controlada democráticamente (Bloom y Risse 2014, 76).

\subsection{Los acuerdos de readmisión}

Un cambio decisivo en la gestión de los flujos migratorios y la lucha contra la inmigración clandestina lo representa la firma de acuerdos de readmisión (en adelante ARUE), con base jurídica, tras la reforma operada por el Tratado de Lisboa, en el párrafo tercero del artículo 79 del TFUE ${ }^{24}$. Estos acuerdos constituyen un compromiso de cooperación recíproca entre la Unión Europea y sus socios de terceros países, con el fin de retornar a sus Estados de origen o de procedencia a los nacionales de terceros países, o nacionales de terceros países en tránsito y apátridas, que no cumplan o que hayan dejado de cumplir las condiciones de entrada, presencia o residencia en el territorio de uno de los Estados miembros. En suma, estos acuerdos facilitan, de un lado, la expulsión de personas en situación de irregularidad administrativa, y de otro lado, la readmisión de estas personas en sus respectivos países o en países terceros ${ }^{25}$. Hasta el momento, la Comisión europea ha sido autorizada para la negociación de veintidós acuerdos de readmisión, de los cuales diecisiete están ya en vigor ${ }^{26}$.

24 No obstante, desde la entrada en vigor del Tratado de Ámsterdam en 1999, era posible negociar y concluir acuerdos de readmisión con terceros países, pues se otorgaba a la Comunidad competencias en esta materia. Así, este tipo de acuerdos ya formaban parte de una estrategia política de la Unión Europea, pactada en el marco de los Consejos Europeos de Tampere (15 y 16 de octubre de 1999, párr. 27), Laeken (14 y 15 de diciembre de 2001, párr. 40) y Sevilla (21 y 22 de junio de 2002, párr. 30).

25 Algunos acuerdos de readmisión, no todos, incorporan una obligación de tránsito, con vistas a facilitar la devolución de nacionales de terceros países a Estados vecinos de las Partes contratantes, "siempre y cuando el Estado requirente no haya podido devolverlos directamente al Estado de destino y necesite cruzar por el territorio del Estado con el que se suscribe el acuerdo de readmisión» (Arenas 2011, 14).

26 Ha sido autorizada para negociar acuerdos con Rusia, Marruecos, Pakistán, Sri Lanka, Ucrania, las regiones administrativas especiales chinas de Hong Kong y Macao, Argelia, Turquía, Albania, China, la Antigua República Yugoslava de Macedonia, Serbia, Montenegro, Bosnia-Herzegovina, la República de Moldova, Georgia, Cabo Verde, Túnez, Armenia, Azerbaiyán, Bielorrusia y Nigeria. Concretamente, están en vigor los acuerdos con las dos regiones administrativas especiales de China, Sri Lanka, Rusia, Ucrania, los países de los Balcanes Occidentales, la República de Moldova, Georgia, Turquía, Armenia, Azerbaiyán, Cabo Verde y Pakistán. Conviene tener presente que, entre los incentivos para la celebración de acuerdos de readmisión, los terceros países 
Sin embargo, en el terreno de la política de readmisión con terceros países han aparecido unas zonas grises u opacas protagonizadas por los nuevos acuerdos prácticos de retorno 27 : atípicos, flexibles, e informales, concluidos al margen del procedimiento de celebración de tratados internacionales previsto en el artículo 218 del TFUE y que, por consiguiente, escapan al control democrático que ejerce el Parlamento Europeo en el marco del procedimiento legislativo ordinario ${ }^{28}$ y a una eventual fiscalización por el TJUE. A esto hay que añadir otro modelo singular de gestión conjunta de la migración que no ha estado ajeno a la polémica; se trata de la Declaración UE-Turquía, de 18 de marzo de 2018, difundida mediante el comunicado de prensa n. ${ }^{\circ}$ 144/16, en virtud de la cual este país accedía, desde marzo de 2016, de forma temporal y extraordinaria según la Comisión, al retorno de inmigrantes irregulares y solicitantes de asilo llegados a las islas griegas

(es el caso de Túnez y Marruecos) reclaman a la Unión Europea la celebración de acuerdos de facilitación de visados en beneficio de sus nacionales, así como ayuda financiera para la aplicación de los mencionados acuerdos. Por otra parte, otros países cooperan en la readmisión de sus nacionales con arreglo al derecho internacional: sirva como ejemplo el artículo 13, párrafo 5, del acuerdo de Cotonú celebrado con el grupo de países de África, Caribe y Pacífico (ACP). Según un informe reciente las operaciones de retorno, 135 en octubre de 2017, han involucrado fundamentalmente a Alemania, Italia, Francia, Bélgica y Austria, operaciones apoyadas en muchos casos por la Agencia Europea de la Guardia de Fronteras y Costas. Cfr. Progress report on the Implementation of the European Agenda on Migration, COM (2018) 250 Final, Bruselas, 13.03.2018, pp. 16 y 177. Para finalizar, conviene advertir que los Estados miembros que tuvieran acuerdos de readmisión de carácter bilateral los mantendrán vigentes en la medida en que no sean incompatibles con los acuerdos celebrados en el plano europeo.

27 La Comisión da cuenta de que «en 2017 se han producido avances significativos con la celebración de varios nuevos acuerdos prácticos». Comunicación de la Comisión al Parlamento Europeo, al Consejo Europeo y al Consejo, Informe de situación sobre la aplicación de la Agenda Europea de Migración, COM (2018) 301 final, Bruselas, 16.05.2018, p. 17.

28 Así, por citar un ejemplo, la Unión Europea y Etiopía firmaron, en noviembre de 2015, un Programa Común de Movilidad y Migración, tratándose de un país de origen, tránsito y destino de los migrantes procedentes del Cuerno de África en su ruta hacia Europa, que si bien no incluye la negociación de acuerdos de readmisión, sí contempla la gestión de la migración mixta, incluida la gestión de la migración irregular. En esta línea, se ha señalado que «la adopción de acuerdos flexibles sobre la readmisión de migrantes sin seguir los procedimientos exigidos por el artículo 218 del TFUE, entre ellos el control democrático del Parlamento, refuerza la (no)certeza legal sobre los términos de los acuerdos: impide la debida responsabilidad democrática y la supervisión judicial; somete la aplicación del acuerdo a la salud de las relaciones diplomáticas; y también diluye responsabilidades y procedimientos de seguridad. De esta manera, estos acuerdos flexibles aumentan el riesgo de violaciones de los derechos fundamentales para los migrantes y refugiados detenidos» (Cassarino y Giuffré 2017,4). 
desde Turquía, y cuyas solicitudes de asilo se hubieran declarado inadmisibles ${ }^{29}$.

Aun cuando el nuevo Marco de Asociación con terceros países en el contexto de la Agenda Europea de Migración exige el respeto pleno de los imperativos humanitarios y un elevado nivel de protección de los derechos fundamentales ${ }^{30}$, estos acuerdos de readmisión plantean muchos problemas desde la óptica del respeto a los derechos humanos más básicos ${ }^{31}$. Estos problemas se sitúan en un triple nivel: en el momento de la negociación de los acuerdos, en el de la adopción de la decisión de devolución de una persona en virtud de estos acuerdos y, una vez que ésta se ha realizado, en el seguimiento de la situación en que se encuentran, fuera ya del territorio europeo, esas personas.

Ciertamente, se ha apuntado la necesidad de que la UE examine el historial de derechos humanos del país con el que está negociando un acuerdo de readmisión para garantizar un regreso seguro de los repatriados (Arenas 2011, 39). Esto se refiere, en particular, al

29 Disponible en https://www.consilium.europa.eu/es/press/press-releases/ 2016/03/18/eu-turkey-statement/ (consultada el 11 de octubre de 2018). Conviene recordar que el Tribunal de Luxemburgo desestimó un recurso de anulación interpuesto contra la mencionada Declaración, con arreglo al artículo 263 del TFUE, porque consideró que no era competente para pronunciarse sobre la legalidad de un acuerdo internacional celebrado por los Estados miembros y el ministro turco. El Consejo y la Comisión, en sus alegaciones, negaron que se tratase de un acuerdo internacional en sentido estricto, ya que este compromiso político era fruto de un diálogo internacional entre los Estados miembros y Turquía que tuvo lugar en una reunión mantenida al margen y con posterioridad a la sesión del Consejo Europeo. Auto del Tribunal General (Sala Primera ampliada), de 28 de febrero de 2017, en el asunto T-257/16, apdos. 71-73, ECLI:EU:T:2017:130.

30 Comunicación sobre la creación de un nuevo Marco de Asociación con terceros países en el contexto de la Agenda Europea de Migración, COM (2016) 385 final de 7.6.2016, p. 2. En esta comunicación se prevé el desarrollo de incentivos positivos y negativos en la política de desarrollo y en la política comercial que se guiará por la capacidad y voluntad del tercer país socio de cooperar en la gestión de la migración (p. 19).

31 Uno de los casos más recientes lo ofrece el polémico acuerdo entre Italia y Libia. Tal y como ha denunciado recientemente la ONG Global Legal Action Network, los que sobreviven a un naufragio y son devueltos por las autoridades libias a tierra firme han sufrido detenciones en condiciones infrahumanas, palizas, torturas, extorsión, hambre, violaciones y esclavitud; motivando por ello la primera denuncia contra Italia ante el Tribunal Europeo de Derechos Humanos. Se centra en un incidente ocurrido el 6 de noviembre de 2017, cuando los guardacostas libios presuntamente obstaculizaron los intentos del barco de una ONG de rescatar a 130 migrantes de una zodiac que se hundía. Murieron unas 20 personas y las que sobrevivieron fueron «llevadas de vuelta» a Libia. Según la demanda, allí las detuvieron y sometieron a violencia extrema y un tratamiento inhumano, y dos supervivientes fueron «vendidos» y electrocutados. 
riesgo de que el país de expedición o readmisión no cumpla con sus obligaciones derivadas de la Convención de Ginebra sobre el Estatuto de los Refugiados de 1951, y de su Protocolo de 1967 y, en su caso, de la Convención Europea de Derechos Humanos y Libertades Fundamentales de 1950. En su reciente Resolución 2228 (2018), la Asamblea Parlamentaria del Consejo de Europa ha puesto de relieve que el cambio de responsabilidades a través del reclutamiento de terceros países para reforzar los controles fronterizos de la Unión Europea conlleva graves peligros para los derechos humanos, dado que aumenta el riesgo de que los migrantes queden «varados» en los países de tránsito a través de la readmisión, así como el incremento de medidas punitivas y restrictivas, como la devolución, la detención arbitraria y los malos tratos. También es una forma de que muchos Estados miembros de la Unión Europea se alejen de un tema que políticamente crea divisiones, como es el de asistir e integrar a los refugiados. Y termina diciendo que mantener a los migrantes a una mayor distancia también puede, de hecho, proporcionar un medio para evitar situaciones de devolución dentro de Europa ${ }^{32}$.

De otro lado, la expulsión de un solicitante de asilo a través de un procedimiento de readmisión que le niega la posibilidad de una revisión individual de su caso, supone una infracción del Derecho internacional y, particularmente, del principio de no devolución (Rais 2016, 45). Conviene tener en cuenta que, en el plano interno comunitario, la célebre Directiva de Retorno constituye «un límite a las facultades soberanas que los Estados miembros» ejercieron de manera discrecional hasta ese momento, «límites que vienen dados por los derechos fundamentales como principios generales del derecho comunitario, así como del Derecho Internacional, incluida la protección de los refugiados y las obligaciones en materia de derechos humanos» (Fajardo 2009, 454-455). La evaluación de que el Estado tercero es un "país seguro» corresponde pues a los Estados miembros, operación que debe tener lugar con carácter previo a la decisión de retorno. Pero, además, si la persona solicita la protección internacional, puede permanecer en el territorio del Estado miembro hasta que se adopte una decisión definitiva sobre la solicitud. No es de extrañar, pues, que el TJUE recientemente haya puesto de relieve que «las Directivas 2008/115 y 2013/32 deben interpretarse en el sentido de que se oponen a que un nacional de un tercer país cuya

32 Resolution 2228 (2018). Text adopted on 27 June 2018 (24th sitting). Human rights impact of the «external dimension» of European Union asylum and migration policy: out of sight, out of rights?, párr. 4. 
solicitud de protección internacional ha sido desestimada en primera instancia por la autoridad administrativa competente, por considerarla manifiestamente infundada, sea internado con vistas a su expulsión cuando, con arreglo al artículo 46, apartados 6 y 8, de la Directiva 2013/32, esté legalmente autorizado a permanecer en el territorio nacional en espera del resultado del recurso presentado contra la decisión por la que se ha desestimado su solicitud de protección internacional» ${ }^{33}$.

En otro orden de cuestiones, no admite discusión que nadie debe ser devuelto en virtud de un acuerdo de readmisión si ello implica el riesgo de que la persona afectada sea objeto de persecución, tortura o castigos inhumanos o degradantes, como proscribe el artículo 19 de la Carta de Derechos Fundamentales de la Unión Europea. En la Sentencia histórica, de 23 de febrero de 2012, en el asunto Hirsi Jamaa e.a c. Italia ${ }^{34}$, el TEDH señaló que "siempre que se demuestre la existencia de motivos sustantivos para creer que el individuo en cuestión, si fuera expulsado, estaría expuesto a un riesgo real de ser sometido a tratos contrarios al artículo 3 en el país receptor», existe «la obligación de no expulsar al individuo a ese país» ${ }^{35}$. Aunque el Tribunal, en el caso de autos, fue consciente de la carga y la presión que la creciente llegada de inmigrantes y solicitantes de asilo suponía para los Estados miembros en cuestión, en un contexto general de crisis económica, sin embargo, apreció que estas últimas consideraciones no pueden eximir a los Estados de sus obligaciones derivadas de esta disposición del Convenio, habida cuenta su carácter absoluto ${ }^{36}$. De forma que Italia, sostenía el Tribunal, no podía «eludir sus propias responsabilidades invocando las obligaciones derivadas de sus acuerdos bilaterales con Libia» ${ }^{37}$, ya que está obligado a no devolver a ninguna persona a un tercer país, aunque este sea firmante de un acuerdo de

33 Auto del TJUE (Sala Primera), de 5 de julio de 2018, as. C-269/18 PPU, C.J.S. C. Staatssecretaris van Veiligheid en Justitie, apdo. 55, ECLI:EU:C:2018:544.

$34 \mathrm{TEDH}$ (Gran Sala), Sentencia de 23 de febrero de 2012, demanda n. ${ }^{\circ}$ 27765/09. Se trataba de una demanda interpuesta por once ciudadanos somalíes y trece ciudadanos eritreos, que interceptados por buques del servicio de vigilancia aduanera de la policía italiana a 35 millas del Sur de Lampedusa, dentro del área de responsabilidad maltesa, alegaron que su deportación a Libia, por mor de un acuerdo bilateral de readmisión de 2009, supuso una violación del artículo 3 del CEDH y del artículo 4 de su Protocolo n. ${ }^{\circ} 4$, así como la falta de vías de recurso, al amparo del artículo 13 del Convenio, que hubieran podido subsanar los agravios sufridos (Castro, 2013).

35 Apdo. 114.

36 Apdo. 122.

37 Apdo. 129. 
readmisión, donde puedan ser sometidos a tortura, trato inhumano o degradante. El Tribunal tuvo presente, además, que Libia es un país intermediario, que no es parte contratante del Convenio sobre el Estatuto de Refugiado y donde se llevan a cabo expulsiones colectivas de inmigrantes y solicitantes de asilo, de manera que no ofrece garantías suficientes para la repatriación segura a los países de origen (Somalia y Eritrea, en este supuesto), donde, por lo demás, también existía la posibilidad de que fueran sometidos a tortura u otras formas de malos tratos.

Italia ofreció a la Comisión europea garantías de obrar de acuerdo con la mencionada sentencia, en particular por lo que se refiere a los acuerdos bilaterales existentes o futuros acuerdos concluidos con Libia $^{38}$. Pero, precisamente, hace unos meses, la Resolución 2215 (2018) de la Asamblea Parlamentaria del Consejo de Europa volvía a hacer un llamamiento a sus Estados miembros, y en particular a aquellos que son también Estados miembros de la UE, para cumplir sus obligaciones al amparo del mencionado artículo 3 del CEDH, esto es, abstenerse de enviar migrantes a países donde estén expuestos al riesgo de sufrir torturas o tratos inhumanos o castigos degradantes. En esta resolución, justamente, se pone en duda que este riesgo no sea real en Libia, país en el que se han detectado situaciones o condiciones de esclavitud, según información contenida en informes recientes elaborados en el marco de las Naciones Unidas o por organizaciones no gubernamentales dedicadas a la protección internacional de los derechos humanos ${ }^{39}$. Conviene añadir, para finalizar, que al menos en el plano teórico, esta sentencia ha tenido reflejo en el Reglamento comunitario por el que se establecen normas para la vigilancia de las fronteras marítimas exteriores, cuyo considerando 12 establece que la observación plena del principio de no devolución, definido en la Carta, tal como ha sido interpretado por la jurisprudencia del TJUE y del TEDH, conlleva que «ninguna persona debe ser desembarcada en un país, forzada a entrar en él ni entregada, de la manera que sea, a sus autoridades cuando exista un riesgo grave de que se vea expuesta a sufrir pena de muerte, tortura, persecución o cualquier otra pena o trato inhumano o degradante, entre otros casos, o cuando su vida o su libertad estén amenazadas por motivos de raza, religión, nacionalidad,

38 Cfr. Informe de la Comisión al Parlamento Europeo y al Consejo. Tercer informe semestral de funcionamiento del Espacio Schengen 1 de noviembre de 2012-30 de abril de 2013, COM (2013) 326 FINAL, ap. 3.3.

39 The situation in Libia: prospects and role of the Council of Europe, adoptada en el debate que se desarrolló el 25 de abril de 2018, párrs. 7 y 8. 
orientación sexual, pertenencia a un determinado grupo social u opinión política, o cuando exista un riesgo grave de que sea expulsada, trasladada o extraditada a otro país incumpliendo el principio de no devolución» ${ }^{40}$.

Por último, se discute la falta de garantías procedimentales explícitas en los acuerdos de readmisión que permitan asegurar que los retornos de personas en situación irregular hacia los Estados requeridos se realicen con arreglo a la protección internacional de los derechos humanos. La propia Comisión europea en su hasta ahora primer y único informe sobre la evaluación de los acuerdos de readmisión, de 2011, reconocía que estos carecen de medios que permitan comprobar el respeto de los derechos humanos de las personas que son devueltas en virtud de estos. De forma particular, esta institución destacaba la ausencia de un mecanismo "postretorno», con vistas a recoger información sobre la situación de las personas readmitidas en el marco de un ARUE, incluido el respeto de sus derechos humanos. En este mismo documento, la Comisión formulaba recomendaciones sobre la futura política de readmisión, incluidos mecanismos para controlar la aplicación de los acuerdos y mejorar las garantías relativas a los derechos humanos, que pasaban por reforzar las funciones encomendadas a los Comités Mixtos de Readmisión. En efecto, en la mayoría de los acuerdos de readmisión existen estos Comités que son órganos políticos copresididos por la Comisión, que en ocasiones está asistida por expertos de los Estados miembros, y los terceros países en cuestión. La Comisión se mostraba favorable a invitar a las reuniones de los mencionados Comités a las ONG y a las organizaciones internacionales, a fin de garantizar en la práctica la interacción adecuada entre la política de retorno y los derechos humanos y las normas de protección internacional. Estos Comités, a su vez, podrían recabar información sobre el terreno procedente de fuentes como las Embajadas de los Estados miembros y las Delegaciones de la Unión Europea, aparte de las ONG y las organizaciones internacionales pertinentes ${ }^{41}$. En una línea similar se había pronunciado la Asamblea Parlamentaria del Consejo de Europa, que pidió a la UE la instauración de mecanismos apropiados para supervisar la implementación, por parte de los Estados miembros, de los acuerdos de readmisión, así como para garantizar que éstos

40 DO L 189 de 27.6.2014, pp. 93-107, en p. 95.

41 Comunicación de la Comisión al Parlamento Europeo y al Consejo, Evaluación de los acuerdos de readmisión de la Unión Europea COM (2011) 76 final, de 23 de febrero de 2011, especialmente las pp. 10-14. 
prevean un sistema bajo el cual su aplicación pueda ser monitorizada y evaluada adecuadamente. Concretamente, aconsejaba la elaboración de un informe anual público por parte de las autoridades del país de readmisión en el que se incluyeran, como mínimo, datos estadísticos sobre el destino de las personas readmitidas y sobre cuestiones tales como detención, liberación, expulsión, acceso al sistema de asilo, etc. ${ }^{42}$. En definitiva, se trata de que el derecho a solicitar asilo, el principio de no devolución, así como la prohibición de las expulsiones colectivas, sean efectivamente garantizados.

\subsection{La instalación de concertinas y las devoluciones en frontera}

Algunos teóricos niegan el carácter coactivo de los controles fronterizos señalando que únicamente debería hablarse de coacción para referirse a las medidas necesarias que, de forma directa, face to face, pueden forzar físicamente la acción de una persona de cara a prevenir una violación de la ley o hacer cumplir una sanción, pero no cuando se amenaza con determinados males si se lleva a cabo cierto tipo de acción. Si las sanciones son previsibles y aplicadas de modo imparcial, el destinatario de la amenaza puede evitarlas adoptando el curso de acción (u omisión) que pretende el autor de la amenaza, por lo que únicamente los actos de imposición física de ciertos males y no la amenaza de aplicarlos serían genuinamente coactivos (Miller 2010, 113-117; Hayek 1960, 133-134). Las autoridades españolas han utilizado un argumento muy similar para justificar la instalación de concertinas en las vallas de Ceuta y Melilla: esto es, que son solo disuasorias y, en el peor de los casos, solo provocan heridas leves en los inmigrantes. Se trata, no obstante, de un planteamiento muy cuestionable, tanto en el plano de la teoría jurídica como en el éticopolítico. Que la sanción sea evitable no significa que también lo sea la amenaza de ella, ni su fuerza para alterar la conducta de la persona a la que intencionalmente se dirige (Schauer 2015, 128-129, Raz 2002, 157). Cabría hablar, en todo caso, de "coacción disuasoria» (López Sala 2015, 523-526), y no de simple disuasión. Pero es que, además, las concertinas, instaladas, retiradas, y de nuevo instaladas en Melilla, al provocar graves lesiones, son una medida inhumana y contraria al Estado de Derecho por atentar contra la integridad física y los derechos humanos de las personas migrantes y refugiadas.

42 Resolution1741 (2010), adopted on 22 june 2010 (22nd Sitting), Readmission agreements: a mechanism for returning irregular migrants, párr. 6. 
Otro tanto cabe decir de las devoluciones en frontera. Tras la promulgación de la Ley Orgánica 4/2015, de protección de la seguridad ciudadana, se insertó la nueva figura legislativa del rechazo en frontera, estrechamente vinculado al concepto operativo de frontera y a la práctica de las expulsiones colectivas, estas últimas prohibidas categóricamente en el párrafo primero del artículo 19 de la Carta de los Derechos Fundamentales de la Unión Europea. En efecto, como se ha indicado, muchos de "los inmigrantes irregulares que son detenidos por la Guardia Civil en el perímetro fronterizo son "rechazados en frontera», e inmediatamente devueltos a Marruecos, esto es, sin llevar a cabo procedimiento administrativo o judicial alguno, en lo que la doctrina ha calificado como devoluciones o expulsiones «en caliente» (López-Jurado 2017, 72). De ahí que, al objeto de examinar la legalidad de éstas ${ }^{43}$, resulte imprescindible profundizar en los argumentos desarrollados por el Tribunal Europeo de Derechos Humanos, en el asunto N.D. y N.T. contra España ${ }^{44}$. Baste con recordar que, en el caso de autos, un nacional marfileño y un nacional maliense alegaban una violación del artículo 3 del CEDH y del artículo 4 del Protocolo n. ${ }^{\circ} 4$, ambos artículos puestos en relación con el artículo 13 del Convenio, tras su rechazo y envío inmediato a Marruecos y ante la ausencia de un recurso efectivo a este respecto. Precisaban que habían sido objeto de una expulsión colectiva, que no habían tenido ninguna posibilidad de ser identificados, ni de alegar sus circunstancias individuales y de los malos tratos a los que, según ellos, corrían el riesgo de ser sometidos en Marruecos, y de impugnar su rechazo mediante un recurso con efecto suspensivo. Lo primero que hizo el Tribunal fue admitir, en contra de lo que sostenía el Gobierno español, que no había duda de que los demandantes se encontraban bajo control continuado y exclusivo de las autoridades españolas, y que fueron expulsados y devueltos a Marruecos contra su voluntad, lo que constituye claramente una expulsión con arreglo al artículo 4 del Protocolo n. ${ }^{\circ}$. Asimismo, el Tribunal constató que, en el caso de autos, las medidas de expulsión habían sido tomadas en ausencia de decisión administrativa o judicial previa. De forma que la cuestión de las garantías suficientes que acreditan una consideración

43 Para un examen de las razones para considerar ilegales las devoluciones en caliente, tanto antes como después de la reforma en abril de 2015 de la Ley Orgánica 4/2000 que incluye, a través de la Disposición adicional décima, los «rechazos en frontera» vid. Martínez Escamilla 2017.

44 TEDH, Sentencia de 3 de octubre de 2017, Demandas n. ${ }^{\circ} 8675 / 15$ y 8697/15, apdos. 105-108. 
real y diferenciada de las circunstancias de cada una de las personas afectadas ni siquiera se plantea en este asunto, en ausencia de todo examen de las circunstancias individuales de los demandantes, al no haber sido éstos objeto de ningún procedimiento de identificación por parte de las autoridades españolas. A la vista de estas consideraciones, el Tribunal concluyó que el procedimiento seguido no permite de ningún modo dudar del carácter colectivo de las expulsiones criticadas.

Pero es que, además, la técnica del rechazo en frontera se ha aplicado igualmente en el ámbito marítimo, cuando ello no sería posible, según la legalidad vigente, "dado que en el mar no hay "elementos de contención" fronterizos» (López-Jurado 2017, 77). Así ocurrió en los sucesos dramáticos de la Playa de Tarajal, el 6 de febrero de 2014, cuando quince inmigrantes fallecieron ahogados al tratar de alcanzar la costa de Ceuta, como consecuencia de una operación en la que los agentes de la Guardia Civil lanzaban material antidisturbios al mar.

Como puede apreciarse, la expulsión de las personas que logran entrar irregularmente atravesando el Mediterráneo en España y Europa constituye, sin duda, uno de los aspectos más controvertidos del control de fronteras. Hay diversas dimensiones de las medidas dirigidas a ponerlas en marcha que merecen una atención especial desde el paradigma de los derechos humanos. De ahí que resulte muy conveniente reflexionar sobre la transposición y aplicación interna de la conocida como la Directiva de Retorno y analizar si, en la práctica, tal y como la misma exige, las decisiones de expulsión y retorno están respetando los principios de «trato justo y trasparente» y «respetuoso con las garantías jurídicas», y observando la Convención Europea de Derechos Humanos.

\subsection{Los Centros de Internamiento de Extranjeros}

Particularmente polémica resulta la aplicación de las medidas de reclusión que la Directiva de Retorno contempla para aquellas personas sobre las que pesa un expediente de expulsión a través de los conocidos Centros de Internamiento para Extranjeros (por sus siglas, (IE). Desde hace años, éstos se hallan en el foco de las críticas no sólo de las ONG y algunos partidos políticos, sino también del Comité de Derechos Humanos de las Naciones Unidas, el Comité para la Prevención de la Tortura del Consejo de Europa, el Relator Especial de las Naciones Unidas sobre los derechos humanos de los migrantes, el Defensor del Pueblo o la Fiscalía General del Estado. 
Pese a proclamarse su carácter no penitenciario (a excepción del internamiento de los extranjeros penados a los que se ha sustituido el cumplimiento de la pena de prisión por la expulsión en virtud del artículo 89.6 del Código Penal, con el fin de asegurarla), las condiciones de vida de las personas recluidas en estos centros son, en muchos casos, claramente carcelarias. Los espacios de uso común son reducidos, existe restricción en los horarios de acceso y los internos pasan la mayor parte del día en los pasillos y el comedor. En su Informe Anual de 2017, el Defensor del Pueblo señala la necesidad de dotar de manera urgente a todos los centros de internamiento de mobiliario suficiente tanto en la zona de ocio como en la de descanso, así como con un receptor de televisión, y también con prensa diaria, biblioteca, juegos de mesa u otros elementos recreativos. En algunos de ellos, además, resulta especialmente grave la ausencia de retretes en el interior de los dormitorios, el uso de candados como mecanismo de cierre de los mismos, y las condiciones de las zonas dedicadas a las visitas, que impiden el contacto físico entre los internos y sus visitantes ${ }^{45}$.

Estas situaciones responden, en gran medida, a que, durante años, desde su creación hasta la publicación del RD 162/2014, de 14 de marzo, por el que se aprueba el Reglamento de funcionamiento y régimen interior de los centros de internamiento de extranjeros, la dirección y gestión de estos centros ha estado completamente en manos policiales ${ }^{46}$. Esto ha motivado que se configuren como contextos opacos, ajenos a las miradas del exterior, en los que la gestión policial no se siente cuestionada, ni por las recomendaciones del Defensor del Pueblo, ni por los autos judiciales de los juzgados de instrucción con competencias específicas en el control de este tipo de internamientos (García España 2017, 2).

45 No existe un médico regular ya que el servicio lo prestan empresas privadas subcontratadas que trabajan en horarios limitados, por lo que, fuera de este tiempo, los internos carecen de cobertura médica. A esto se suman las múltiples denuncias sobre la negativa de los funcionarios para que los internos accedan a visitas médicas; este ha sido considerado uno de los motivos del fallecimiento de una interna en el CIE de Aluche en Madrid el 19 de diciembre de 2011 y de un interno en el CIE de la Zona Franca de Barcelona el 6 de enero de 2012. Vid. González Beyllfus (2017), Ríos Martín et al. (2014).

46 Actualmente, aunque la dirección del centro continúa correspondiendo a la Policía Nacional, se introduce la figura del administrador (artículo 12 del Reglamento de los Centros de Internamiento para Extranjeros), funcionario no policial que ostentaría las funciones de dirección de los servicios asistenciales, administrativos y logísticos, así como la recepción de las quejas y sugerencias de los internos. Sin embargo, no hay constancia de que este precepto haya sido aún implementado. 
Pero es que, más allá de las calamitosas condiciones de internamiento en los CIE españoles, el mero hecho de habérsele reconocido cabida en nuestro sistema jurídico resulta muy cuestionable y lesivo para derechos fundamentales básicos. Ni la sentencia del Tribunal Constitucional 115/1987, que resuelve el recurso del defensor del Pueblo contra la LO 7/1985, por entender que la creación de los CIE vulneraba el artículo 25.3 CE, ni la jurisprudencia del TEDH que, de acuerdo con el artículo $5.1 \mathrm{~g}$ ) del $\mathrm{CEDH}^{47}$, avala la posibilidad de detención de una persona en el caso de que se encuentre inmersa en un proceso de expulsión o extradición ${ }^{48}$, cierran definitivamente el problema de su corrección constitucional, ni el de su adecuación a los derechos humanos protegidos por la Convención europea.

El alto tribunal salvó en su momento la aparente inconstitucionalidad de lo que no deja de ser una orden de privación de libertad en el marco de un procedimiento administrativo, gracias a que el legislador condicionó el internamiento a su autorización por el juez del lugar donde se produce la detención. Sin embargo, suspender un derecho tan básico como la libertad deambulatoria como garantía de la ejecución de una eventual sanción administrativa, como es la expulsión, genera dudas de constitucionalidad no en relación con el 25.3 sino con el 17.1 de la CE (Martínez Escamilla $2016,20)$. Efectivamente, si se acepta como premisa que la libertad de movimiento es un derecho reconocido a todas las personas

47 El artículo 5 dispone que nadie puede ser privado de su libertad, salvo en los casos siguientes y con arreglo al procedimiento establecido por la ley en ciertos supuesto entre los que incluye en su la letra $f$ «si se trata de la detención preventiva o del internamiento, conforme a derecho, de una persona para impedir que entre ilegalmente en el territorio o contra la que esté en curso un procedimiento de expulsión o extradición».

48 En el asunto Saadi contra Reino Unido, el TEDH sostuvo que una entrada era ilegal hasta que las autoridades nacionales la autorizaran formalmente. En ese asunto, el Tribunal consideró que no se había vulnerado el artículo 5.1, cuando un solicitante de asilo había sido detenido legalmente durante siete días en condiciones adecuadas mientras se tramitaba su solicitud de asilo. TEDH, Saadi contra Reino Unido (Gran Sala), n. ${ }^{\circ}$ 13229/03, 29 de enero de 2008, apdo. 65. Sin embargo, en el asunto Suso Musa contra Malta, el Tribunal consideró que cuando, yendo más allá de sus obligaciones de reconocer derechos adicionales o una posición más favorable (una posibilidad que se le ofrece de conformidad con el artículo 53 del Convenio), un Estado promulgue una legislación (por propia iniciativa o de conformidad con el derecho de la Unión Europea) que autorice explícitamente la entrada o la permanencia de inmigrantes en espera de una solicitud de asilo, la detención subsiguiente con el fin de prevenir una entrada no autorizada puede plantear la cuestión de la legalidad de la detención a la luz del artículo 5.1. TEDH, Suso Musa contra Malta, n. ${ }^{\circ}$ 42337/12, 23 de julio de 2013, apdo. 97. 
y no sólo a los ciudadanos ${ }^{49}$, y que los derechos fundamentales constituyen "triunfos» (Dworkin), "cotos vedados» (Garzón Valdés, 1993) a las negociaciones y cálculos basados en consideraciones de utilidad política y social, la justificación del internamiento en los CIE no puede ser únicamente asegurar la máxima eficacia de las expulsiones, sino que es preciso que entre también en juego el juicio de proporcionalidad. Este exigiría que las ventajas derivadas de la existencia de los CIE, tanto en la esfera individual o colectiva, compensen la limitación de derechos que conlleva. Los criterios de ponderación serían, en tal caso, los siguientes: a) si se trata de asegurar expulsiones de naturaleza administrativa y no penal (el aseguramiento de las segundas tendría más peso); b) si resulta viable su ejecución sin recurrir al internamiento (el porcentaje de personas repatriadas desde los diferentes CIE fue en 2016 del 29 por ciento, mientras que en 2017 aumentó ligeramente, hasta el 32 por ciento); c) la naturaleza jurídica y constitucionalidad de la detención. A la vista de todo ello, no parece que exista un equilibrio razonable entre los beneficios y perjuicios derivados de la existencia de los CIE (Martínez Escamilla 2016, 33-34).

Otro tanto cabe afirmar de la jurisprudencia del TEDH. Este se limita a exigir que las detenciones que ampara el artículo $5.1 \mathrm{f}$ ), no sean arbitrarias, en el sentido exigido por una visión estrictamente formal de la seguridad jurídica (claridad, precisión, previsibilidad), se lleven a cabo de buena fe, estén estrechamente conectadas con el propósito de evitar el ingreso no autorizado de la persona al país, que el lugar y las condiciones de detención sean apropiadas, teniendo en cuenta que la medida no es aplicable a quienes han cometido delitos penales y que su duración no exceda de lo razonablemente requerido para el propósito perseguido ${ }^{50}$. Sin embargo, a diferencia de los supuestos contemplados en las letras a), b), c) y d) y e) del artículo 5, que la decisión del Estado sea sometida a los test de necesidad y proporcionalidad de la detención no exige que se haya sopesado el perjuicio ocasionado a la persona

49 Un ejemplo contrario sería la línea jurisprudencial seguida por el Tribunal Constitucional español a la hora de interpretar el artículo 17.1 de la Constitución en relación con los extranjeros. Las SSTC 107/1984 (F.J.3) de 23 de noviembre, 94/1993 de 22 de marzo, 116/1993, de 29 de marzo, 260/2007, de 20 de diciembre (FJ.5), sostienen que la libertad de circulación a través de las fronteras del Estado, y el concomitante derecho a residir dentro de ellas, no son derechos imprescindibles para la garantía de la dignidad humana, ni por consiguiente pertenecen a todas las personas en cuanto tales al margen de su condición de ciudadano.

50 TEDH Ryabikin contra Russia, Sección 1a 19.9 .2008 (n. $\left.{ }^{\circ} 8320 / 04\right) ;$ TEDH, Saadi contra Reino Unido (Gran Sala), n. ${ }^{\circ}$ 13229/03, 29 de enero de 2008, apdos. 72-73. 
por la privación de su libertad frente a su derecho de control de las fronteras (Fallada 2010).

Por todo ello, y a la vista, fundamentalmente, de que la mayor parte de las personas que pasan por los Centros de Internamiento son puestas en libertad en lugar de expulsadas, y la mayor parte de las expulsadas lo son sin haber estado previamente recluidas en tales centros, cabe concluir que los CIE han desnaturalizado el internamiento como instrumento destinado a asegurar la ejecución de una expulsión o una devolución para terminar convirtiendo tanto la privación de libertad, como las malas condiciones de vida de los internos, en una herramienta de disuasión de la inmigración irregular (Boza 2017,110-111; García España 2016). Queda por ver cómo puede afectar a la existencia de los CIE el reciente acuerdo del Consejo Europeo de 29 de junio de crear plataformas regionales de desembarco. Estas deben funcionar distinguiendo entre los migrantes irregulares, los que se retornará y las personas necesitadas de protección internacional, a las que se aplicará el principio de solidaridad. Además de desincentivar las peligrosas travesías en el Mediterráneo, el procesamiento fuera de las fronteras de la UE de las demandas de entrada en su territorio evitaría la necesidad de procesos de expulsión y, por tanto, de estos centros de internamiento. Entretanto, resulta inexcusable insistir en medidas alternativas a la reclusión en los centros de internamiento menos invasivas y restrictivas, como las contempladas en el artículo 61.1 Ley Orgánica 4/2000, (la presentación periódica ante las autoridades competentes, la residencia obligatoria en determinado lugar o la retirada del pasaporte), así como en la posibilidad de utilizar mecanismos electrónicos de geolocalización (Boza 2017, 115).

\section{Reflexiones finales}

La superación de los principales déficits de legitimidad de las políticas de control de fronteras desplegadas por la UE exige apostar por un cambio de perspectiva, por adoptar una concepción cosmopolita de la justicia y el derecho y una visión expansiva de la solidaridad, capaz de desanclarla de las comunidades nacionales o los Estados y extenderla trasnacionalmente. En esta línea, recientemente el Consejo Constitucional francés ha consagrado el "principio de fraternidad» como valor constitucional para anular la condena de 2017 de cuatro meses de prisión al conocido agricultor Cédric Herrou por ayudar a migrantes que atraviesan la frontera entre Italia y Francia. Este pedía 
la abolición del llamado «delito de solidaridad» que, si bien no existe formalmente, se aplicaría a quienes transporten o alberguen a los extranjeros en situación irregular. Como también ha señalado De Lucas, resulta fundamental recuperar la relación entre el Estado de Derecho, la democracia y el principio de solidaridad a propósito de los deberes jurídicos correlativos al reconocimiento de los derechos humanos. Para lograrlo, debe apostarse por una concepción de este último valor que, entendido como un principio jurídico y no un simple desiderátum moral, la conciba como una solidaridad inclusiva y tendencialmente universal, que no se cierra en el ámbito del nosotros y que no utiliza la referencia excluyente de los otros desde la exacerbación de la diferencia (Lucas 2014, 50 y 68 ss).

Frente a la tendencia observada a lo largo de los últimos años de abordar la inmigración ilegal como un problema de orden público, como una amenaza para la seguridad de los Estados y, en cualquier caso, como una cuestión nacional o regional, es necesario explorar las alternativas basadas en una visión de las migraciones como un fenómeno global que exige soluciones políticas y jurídicas también globales. Las personas que tratan de traspasar la frontera sur de Europa lo hacen movidas por la necesidad de huir de una pobreza extrema y de escenarios de guerra y persecución política (de ahí que se hable de flujos migratorios mixtos) que son, en gran medida, resultado de un orden internacional. Por lo tanto, resulta inexcusable abordar las medidas basadas en un enfoque sobre las migraciones que tome en consideración el reconocimiento como un auténtico derecho humano de la libertad de circulación a través de las fronteras y de la visión de los migrantes como seres humanos frente a los que tenemos responsabilidades socioeconómicas fuertes, cuya implementación pasaría, entre otras posibles actuaciones (ayuda al desarrollo, condonación de la deuda, reforma del marco jurídico del comercio mundial, introducción de una condicionalidad democrática más exigente en la adquisición de numerosas materias primas y en el comercio de armas, etc.), por una mayor apertura de las fronteras. Como expresó con lucidez Goodin, «if we cannot move enough money to where the needy people are, then we will have to count on moving as many the needy people as possible to where the money is» $(1992,8)$. 


\section{Referencias}

Abizadeh, Arash. 2008. "Democratic Theory and Border Coercion. No Right to Unilaterally Control Your Own Borders", Political Theory, 36 (1): 37-65.

Abizadeh, Arash. 2010. "Closed borders, Human Rights and Democratic Legitimation" en Driven from Home: Protecting the Rights of Forced Migrants, editado por David Hollenbach, 147-166. Washington: Georgetown University Press.

Abrisketa, Joana. 2017. "La dimensión externa del Derecho de la Unión Europea en materia de refugio y asilo: un examen desde la perspectiva del non-refoulement", Revista de Derecho Comunitario Europeo, 56: 119158.

Agamben, Giorgo. 2004. Estado de excepción. Homo Sacer II, Valencia: Pretextos italianos.

Akkermann, Mark. 2018. Expanding the fortress. The policies, the profiteers and the people shaped by UE's border externalization program, Transnational Institute and Stop Wapenhandel, Amsterdam, en https:// www.tni.org/files/publication-downloads/expanding_the_fortress_-_1.6_ may_11.pdf.

Arenas, Nuria. 2011. "El Acuerdo europeo de readmisión de inmigrantes en situación irregular con Pakistán. Punto de inflexión o huida hacia delante", Revista General de Derecho Europeo, 24: 1-40.

Arsenijevic, Jovana; Manzi, Marcel y Zachariah, Rony. 2017. Defending humanity at sea are dedicated and proactive search and rescue operations at sea a "pull factor" for migration and do they deteriorate maritime safety in the central mediterranean?, Médecins sans Frontières, Luxembourg. Acceso el 26 de Septiembre de 2018. http://searchandrescue.msf.org/ assets/uploads/files/170831-\%20Report_Analysis_SAR_Final.pdf.

Attiná, Fulvio. 2018. "Tackling the migrant wave: EU as a source and manager of crisis", Revista Española de Derecho Internacional, 70 (2): 49-70.

Baird, Theodore. 2017. "Carrier sanctions in Europe: A comparison of trends in 10 countries", European Journal of Migration and Law, 19: 307-334.

Baird, Theodore. 2018. "Interest groups and strategic constructivism: business actors and border security policies in the European Union, Journal of Ethnic and Migration Studies, 44 (1): 118-136.

Bayón, Juan Carlos. 2014. "Democracia más allá del Estado". En Entre el Estado y la Cosmópolis. Derecho y Justicia en un mundo global, editado por Alfonso Ruiz Miguel, 121-138. Madrid: Trotta.

Bloom, Tendayi y Risse, Verena. 2014. "Examining hidden coercion at state borders: why carrier sanctions cannot be justified" , Ethics \& Global Politics, 7 (2): 65-82.

Boza, David. 2017. “El internamiento de personas extranjeras: más allá de los límites de la privación de libertad". En Estados de contención, estados de detención. El control de la inmigración irregular en España, coordinado por Ana López Sala y Dirk Godenau, 97-118. Barcelona: Antrophos. 
Cassarino, Jean-Pierre y Giuffé, Mariagiulia. 2017. "Finding its place in Africa: Why has the EU opted for flexible arrangements on readmission", FMU Policy Brief, no. 01/2017.

Castro Sánchez, Claribel de. 2013. "Tribunal Europeo de Derechos HumanosTEDH-Sentencia 23.02.2012 (Gran Sala)-Hirsi Jamaa e.a. c. Italia, 27765/09, "Artículo 3 y 13 del CEDH; Artículo 4 del Protocolo n. ${ }^{\circ} 4$ Tortura y tratos inhumanos y degradantes - derecho a un recurso efectivo prohibición de las expulsiones colectivas de extranjeros", Revista de Derecho Comunitario Europeo, 46: 1119-1135.

Centre Delàs d'Estudis per la Pau. 2018. Indra Sistemas S.A., armas para la guerra y la militarización de fronteras, en http://www.centredelas.org/ images/INFORMES_i_altres_PDF/Fichalndra_CAST_DEF.pdf.

Díez Peralta, Eva, 2017. "La Seguridad Nacional de España y el Mediterráneo". En La Seguridad Nacional en España. Un enfoque geoestratégico, dirigido por Javier Roldán Barbero, 165-222. Valencia: Tirant Lo Blanch.

Fajardo del Castillo, Teresa. 2009. "La Directiva sobre el retorno de los inmigrantes en situación irregular", Revista de Derecho Comunitario Europeo, 33: 453-499.

Fallada, Juan Ramón. 2010. "Algunos límites a los derechos de los inmigrantes: detención y expulsión en la jurisprudencia del Tribunal Europeo de Derechos Humanos", Cuadernos Electrónicos de Filosofía del Derecho, 20: 43-66.

Ferrajoli, Luigi. 1998. Derechos y garantías. La ley del más débil, Madrid: Trotta.

Ferrajoli, Luigi. 2011. Poderes salvajes. La crisis de la democracia constitucional, Madrid: Trotta.

García España, Elisa. 2017. "Centros de Internamiento de extranjeros: motivos para su desaparición", Boletín Criminológico, 172:1-6.

Garzón Valdés, Ernesto. 1993. Ética, Derecho y Política, Madrid: Centro de Estudios Constitucionales.

Ghezelbash, Daniel et al. 2018. "Securitization of search and rescue at sea: the response to boat migration in the Mediterranean and offshore Australia", International and Comparative Law Quarterly, 67: 315-351.

González Beyllfus, Markus. 2017. "Los CIE: una realidad controvertida y compleja", Anuario CIDOB de la inmigración: 298-316.

Goodin, Robert. 1992. "If people were money...". En Free Movement: Ethical Issues in Transnational Migration of People and of Money, editado por Brian Barry y Robert Goodin, 6-22. Pennsylvania: The Pennsylvania State University Press.

Goodwin-Gill, Guy y Mcadam, Jane. 2007. The Refugee in International Law, Oxford: Oxford University Press.

Hayek, Friedich. 1960. The Constitution of Liberty, Chicago: University of Chicago Press.

Lafont, Cristina. 2010. "Responsabilidad, inclusión y gobernanza global: Una crítica de la concepción estatista de los derechos humanos", Isegoría, 43: 407-434. 
Last, Tamara, et al. 2017. "Deaths at the Borders Database: evidence of deceased migrants' bodies found along the southern external borders of the European Union", Journal of Ethnic and Migration Studies 43 (5): 693712 .

López Sala, Ana. 2015. "Dissuasion as a (geo)political instrument in irregular migration control at the Southern Spanish maritime border". Geopolitics, 20: 1-22.

López Sala, Ana y Godenau, Dirk. 2016. "Delegando el control migratorio. Una aproximación a las dinámicas outsourcing en España". En Estados de contención, estados de detención. El control de la inmigración irregular en España, coordinado por Ana López Sala y Dirk Godenau, 197-223. Barcelona: Antrophos.

López Sala, Ana y Godenau, Dirk. 2017. Non-state actors and migration control in Spain. a migration industry perspective, en http://hdl.handle. net/10261/136847.

López-Jurado, Carmen. 2017. "Las fronteras de Ceuta y Melilla: un análisis desde la perspectiva de la seguridad y de los derechos humanos". En La Seguridad Nacional en España. Un enfoque geoestratégico, dirigido por Javier Roldán Barbero, 53-97. Valencia: Tirant Lo Blanch.

Lucas, Javier de. 2014. Mediterráneo: el naufragio de Europa, Valencia: Tirant Lo Blanch.

Mac Namara, Frank. 2017. Externalised and Privatized Procedures of EU Migration Control and Border Management. A Study of EU Member State Control and Legal Responsibility, Tesis doctoral, Instituto Universitario de Florencia.

Martínez Escamilla, Margarita (Coord). 2015. Detención, internamiento y expulsión administrativa de personas extranjeras, Madrid. en: https:// eprints.ucm.es/34492/1/FINAL. \%20DIC\%202015\%20LIBRO\%20CGPJ.pdf

Martínez Escamilla, Margarita. 2016. "Centros de internamiento para extranjeros. Estado de la cuestión y perspectivas de futuro", Revista Electrónica de Ciencia Penal y Criminología, 18: 1-38.

Martínez Escamilla, Margarita. 2016. "Fronteras sin derechos. Las devoluciones en caliente". En Estados de contención, estados de detención. El control de la inmigración irregular en España, coordinado por Ana López Sala y Dirk Godenau, 54-74. Barcelona: Antrophos.

Miller, David. 2010. "Why immigration controls are not coercive: A reply to Arash Abizadeh", Political Theory, 38 (1): 111-120.

Miller, David. 2015. "The duty to rescue boat people", en prensa. Versión provisional en https://ecpr.eu/Filestore/PaperProposal/f629fbdb-6aba-480c95a8-1ba9663f5dba.pdf.

Miller, David. 2016. Strangers in our midst, Massachusetts: Harvard University Press.

Moreno-Lax, Violeta. 2008. "Must EU borders have doors for refugees? On the compatibility of Schengen visas and carriers' sanctions with EU Member States' obligations to provide international protection to refugees', European Journal of Migration and Law, 10: 315-364. 
Peers, Steve. 2016. EU Justice and Home Affairs Law, Oxford: Oxford University Press.

Rais, Medhi. 2016. "Los acuerdos de readmisión de la Unión Europea", Revista de Migraciones Forzadas, 51: 45-46.

Raz, Joseph. 2002. Practical reasons and norms, Oxford: Oxford University Press.

Ríos Martín, Julián; Santos Itoiz, Eduardo y Almeida Herrero, Cristina. 2014. Manual para la defensa de los derechos de las personas extranjeras encerradas en los Centros de Internamiento, San Sebastián: Gakoa.

Schauer, Frederick. 2015. The Force of Law, Cambridge-Massachusetts: Harvard University Press.

Scheurmann, William. 2014. "Cosmopolitanism and the world State", Review of International Studies, 40 (3): 1-23.

Soler, Carolina. 2017. "La Guardia Europea de Fronteras y Costas: ¿Un avance respecto a FRONTEX? Una valoración provisional", Revista Electrónica de Estudios Internacionales, 34: 1-44.

Spijkerboer, Thomas. 2018. "Bifurcation of Mobility, Bifurcation of Law. Externalization of migration policy before the EU Court of Justice", Journal of Refugee Studies, 32(1): 216-239.

Zaiotti, Ruben. 2016. "Mapping remote control. The externalization of migration management in the 21st century". En Externalizing Migration Management: Europe, North America and the Spread of 'Remote Control' Practices, editado por Ruben Zaiotti, 3-30. Routledge: Londres.

Zapata, Ricard. 2013. "La dimensión exterior de las políticas migratorias en el área mediterránea: premisas para un análisis normativo", Revista del Instituto Español de Estudios Estratégicos, 2: 1-38.

Zolberg, Aristide. 2003. "The archeology of 'remote control'". En Migration Control in the North Atlantic World: The Evolution of State Practices in Europe and the United States from the French Revolution to the Inter-War Period, editado por Andreas Fahrmeir, Oliver Faron y Patrick Weil, 195222. Nueva York: Berghan Books. 


\section{Copyright}

Deusto Journal of Human Rights / Revista Deusto de Derechos Humanos is an Open Access journal; which means that it is free for full and immediate access, reading, search, download, distribution, and reuse in any medium only for non-commercial purposes and in accordance with any applicable copyright legislation, without prior permission from the copyright holder (University of Deusto) or the author; provided the original work and publication source are properly cited (Issue number, year, pages and DOI if applicable) and any changes to the original are clearly indicated. Any other use of its content in any medium or format, now known or developed in the future, requires prior written permission of the copyright holder.

\section{Derechos de autoría}

Deusto Journal of Human Rights / Revista Deusto de Derechos Humanos es una revista de Acceso Abierto; lo que significa que es de libre acceso en su integridad inmediatamente después de la publicación de cada número. Se permite su lectura, la búsqueda, descarga, distribución y reutilización en cualquier tipo de soporte sólo para fines no comerciales y según lo previsto por la ley; sin la previa autorización de la Editorial (Universidad de Deusto) o la persona autora, siempre que la obra original sea debidamente citada (número, año, páginas y DOI si procede) y cualquier cambio en el original esté claramente indicado. Cualquier otro uso de su contenido en cualquier medio o formato, ahora conocido o desarrollado en el futuro, requiere el permiso previo por escrito de la persona titular de los derechos de autoría. 